\title{
A Brave New Creativity
}

\begin{abstract}
Anyone who has taught design in higher education for any length of time knows that the parameters of their work have changed. Design is no longer industry based, but seen as an approach, an attitude, with ways of thinking that can contribute to all programs across the university system. Ensuring that this new cohort are engaged in authentic, complex problem based learning and empowered in that learning is a challenge in itself but one of the most important teaching issues is how to instil genuinely creative thinking in students tackling 'messy' problems, unencumbered by the attitudes and approaches of the past. This article discusses the difficulties in achieving the creative learning aims involved, highlights areas that are yet to be resolved and suggests the use of a cognitive apprenticeship model combined with a practical, incremental teaching and assessment model of creativity as a contribution to the way forward.
\end{abstract}

Keywords: Creativity, complex problems, apprenticeship, empowerment, assessment

\section{Introduction}

Over the past two decades, the ontology behind design courses around the world has been repeatedly reviewed and revised, leading towards approaches in design thinking and practice that consider the broader implications of design on environment and societies (Loy 2012). In addition, beyond meeting sustainable design imperatives, there has been a move towards design thinking that actively contributes to contraction and convergent economic theory (Fuad Luke 2009). This has radicalised the content taught at a project level, beyond the shift from designing specific commercial products through product service systems thinking (Hawken, Lovins, Lovins 2008), to projects with far reaching social engineering as their aim and with the politics of design activism embedded in their teaching (de Vere 2011).

In educational terms, this has required design students to develop a far broader understanding of the drivers behind their decisions and has included the intention of making them proactive in leading clients and directing project briefs beyond traditional industry practice. Graduates will need confidence to take on this role and if design education is creating an implied leadership role for new graduates, then it is part of the task of education to inculcate this. To achieve this goal, design education as a discipline needs to be actively working within 
comprehensive design philosophies that position individual as well as group decisions and actions more overtly within a global as well as local context.

To succeed in this aim a holistic approach to thinking, teaching and assessment is prerequisite. The single most important issue in this - the one that informs any holistic, multi-layered, complex approach to problem framing and problem solving — is how to instil genuinely creative thinking into students. To achieve this fully would require institutional change where the disruptive, radical nature of creativity is embraced and not compartmentalized and normalised. Although beyond the scope of this article, this then becomes a challenge to the inherited academic and administrative structures of institutions and the institutional reform necessary to achieve the desired outcome. A starting point for this reform is a review of learning about creativity as a first step that takes into account the shifted role of design in higher education. Ensuring that students are engaged in authentic problem based learning and empowered in that learning, whilst addressing the complexity of projects that are no longer discipline specific, is a challenge in itself. Providing practical support mechanisms for students to embrace creativity in that context needs to be addressed. This article suggests that whilst seemingly inherently contradictory, it is actually possible to provide structure and a holistic creative thinking approach using a cognitive apprenticeship model along with revised practical assessment models of creativity.

In writing about the creative future of education, Craft calls for 'wise creativity' and 'collective creative trusteeship', emphasising that, 'creative educational futures demand consideration of fundamental change to how we conceive of curriculum, pedagogy and learning, together with who teaches and who learns, where, how and why' (Craft 2008:11). Understanding the re-imagining of creativity taking into account the role of pre-configuring (Fry 2011: 204) and the challenges of overcoming collective memory, cultural memes and habitus, is becoming part of the new thinking for learning and teaching in design education. Students following this new approach to design curriculum will have to learn to challenge many assumptions, much of what they have been told and they currently think they know. They will need to be supported by pedagogy that values and promotes genuine creative thinking practices as fundamental to every stage of student development. 


\section{The re-imagining of creativity: from sideshow to centre stage}

Presenting design as pre-configuration requires that the designers of the future approach their role with a far more fundamental shift in thinking than ever before. Supporting students in trying to see past current practices towards the potential futures in front of them from a radically new point of view, uncluttered with expectations of the profession, of current societies' thinking and of their own background is a huge challenge. Providing a practice of enhanced creativity, where students are led through a supported experience of working to meet these expectations and not expected instead to abandon their current beliefs and knowledge with no structure is central to the positive development of more radical strategic design thinking.

Isaac Asimov (Asimov 1987) wrote about a future where education was delivered by tape straight into a student's brain, with the choice of content based on a scan of the individual's brainwaves. Some students could not be programmed, their brainwaves were not organised in a way that could accept blocks of information and Asimov posed that these students were the writers of the future materials for everyone else. Similarly, future designers need to do their best to critically reassess, and in some respects wipe, their programming and to start their journey as aliens. They need to develop an objective view of the world and all that currently populates it, both in terms of attitudes and of systems (such as energy supply and dependence, economics, etc.) that goes beyond a learned body of knowledge to a fundamental change in perspective and in the way they think. Creativity is central to this shift and creativity-focused pedagogy is an essential starting point for initiating re-directive design practice.

\section{Redesigning creative thinking in education}

Creative thinking as a major area of research study only came to prominence after Guilford gave a seminal address to the American Psychological Association in 1950. Before then, there had been a course in creative thinking at the University of Nebraska, launched by Crawford, whose methods had been made popular through a number of books, whilst Osborn had developed a systematic approach to improve creativity, including 'brainstorming' whose techniques became well-known and widely practiced in education and business (Osborn 1963). Of these, Osborn's 'Creative Problem Solving' (CPS) technique, refined over the years, is seen as the most influential on current teaching practices as it provided the means to develop creative thinking, proving for the first time that creative thinking techniques could 
be learned (Treffinger, Isaksen and Stead-Dorval 2006).

Since Guilford, there has been an exponential expansion of academic research into the subject and building on this a growth industry in applied creative thinking for business practices (e.g. Clegg and Birch 2002; De Bono 1990; Michalko 2001; Pricken 2002). Fundamental to most current approaches to applied creative thinking are divergent and convergent thinking techniques to stimulate and direct this thinking and these are evident in both design teaching and design practice. Divergent thinking is commonly considered to be the essence of creative thinking since this is when many different or unusual ideas or possibilities are generated (it is also termed generative or simply creative thinking). Convergent thinking (also termed analytical, focused or critical thinking) is then applied to each idea to critically assess it in relation to whatever constraints are being applied to the outcome. In creative individuals these processes occur rapidly and repeatedly and are effectively integrated (e.g. Calwelti, Rappaport and Wood 1992) and are associated with the functioning of memory (Gabora 2010). The constant switch between divergent (generative) and convergent (analytical) thinking underlines the complicity of both hemispheres of the brain in the creative process, meaning that the need to locate creativity within an holistic framework that is not simplistically a 'right' brain activity (McGilchrist 2010) and this has implications for teaching and learning within the changing design paradigm being considered here.

Based on recent developments in the design curriculum and resultant need to re-imagine creative thinking for its new role and significance in changing perspectives and practices, supporting learning creativity needs to be reassessed and reinvigorated. Divergent and convergent thinking are still key, but in addition to current practice, they need now to be operated in circumstances that have been set up to ensure that the student does not rely wholly on past experience or understandings. The difficulty is that students will inevitably use thinking that is based on assumptions taken from a pre-set view of the world. It is in challenging these certainties to allow for fresh thinking to emerge that the design educator needs to base newly developed learning situations. A shift to a holistic and imaginative approach is necessary, yet one that does not disengage the learner by being too far beyond their understanding. This is a delicate balance for the educator to provide. 


\section{Authentic learning.}

A distinguishing feature of creative learning well known in design is that there is never one, single, 'correct' outcome or solution. However, projects responding to the search for enhanced creative thinking for the new curriculum need to be organized beyond that idea, to be not predetermined or even pre-imagined by the educator, taking the student on a journey whose outcome is unknown to the lecturer as well as the student. This can only realistically happen if the task works outside the boundaries of the educator's area of expertise as well as that of the students', yet in addition, the students will still need to care about the study in some way to engage effectively (Biggs and Tang 2011) — and that is also true of the lecturers (Ramsden 2003: 86) - and the lecturer will need to be able to project confidence throughout the study in support of the student (difficult in the circumstances) and be sure about assessment criteria. This causes confusion and conflicts that need more attention than is currently being gained from publications on teaching for the emerging design curriculums.

Without predetermination, it is less likely that the students will reach an apparent, recognizable conclusion, so it needs to be very clear to the student that their creative thinking is valued for its own sake, not as working towards any specific solution. The selection of any task that allows for a creative output is always more difficult when 'right' and 'wrong' is replaced with 'more' or 'less'. Such tasks fall into the category of 'authentic' problems; 'an authentic problem (a) does not have a predetermined answer, (b) is personally relevant to the investigator, and (c) can be explored through the methods of one or more disciplines' (Starko, 2010: 16). The curriculum, however, has to include means of assessment to establish the extent to which learning has occurred and this can pose a major hurdle for some educators who may believe, because creativity is difficult to pin down, it is also therefore impossible to assess. Not only is the product variable but the process is also demanding of the lecturer, who must assume the role of both mentor and of co-learner. This is key to the transition from institutionalized methods of learning creative thinking to genuine engagement unencumbered by the assumptions of the academic or the conventions of design practice and needs to be supported with transparent assessment based on shared understandings of quality.

\section{Empowerment.}

Weimer's seminal work on changing the balance of power in the classroom in higher education (Weimer 2002) has never been more relevant than it is now in relation to design 
education. For an enhanced creativity approach, students need to genuinely have power to direct their own learning and work in collaboration with the lecturer, exploring genuinely new ground where no preconceived outcomes are established, rather than be given tutoring by the lecturer in any form of didactic learning situation where their role is passive receiver, not investigator. According to Weimer, in order to create a qualitative change of perception in the students' understanding, as required to promote enhanced creative thinking practices, the whole way activities are framed needs to be learner-centred for deep learning rather than surface learning. The main challenge to didactic learning that Weiner identifies as fundamental for student-centred learning is the importance of creating a shift in the balance of power in the learning experience from the lecturer to the student.

'Students' motivation, confidence and enthusiasm for learning are all adversely affected when teachers control the processes through and by which they learn $[\ldots]$ teacher authority is so taken for granted that most of us are no longer aware of the extent to which we direct student learning' (Weimer 2002: 23).

In order to change the drivers for learning on a course, the student role needs to be established as investigative for the project, rather than as the recipient of knowledge: 'Courses (in student centred learning) are assignment centred rather than text and lecture centred. Goals, methods and evaluation emphasise using content rather than simply acquiring it' (O'Brien, Millis and Cohen 2008: 19). However, in order to fundamentally change the drivers for creative thinking learning on a course, the student role needs to be established as investigative for all aspects of the project, rather than as the investigator for just certain aspects of the learning experience. The starting points for courses in this context will therefore move from providing an introductory lecture that leads practice, followed by set projects with problem based learning as the point of entry, to a truly investigative role where the students explore complex or 'messy' problems that cross discipline boundaries with few parameters given. Whilst working beyond their current understanding is a specific intention for promoting the new approach, there is a concern that students might feel disempowered by the breadth of the task, rather than empowered which is vital for deep learning. In addition, as Jesse Tatum states in his Design Issues article on design responsibility, even the smallest design decision must be treated as vital because of the cumulative effect of incremental change (Tatum 2004). This sense of responsibility can in itself create a barrier to authentic, enhanced creative thinking. Obstacles to enhanced 
creativity need to be mapped and addressed in course design to provide students with the tools to overcome them, but also addressed more fundamentally in the whole way a student is inducted into higher education and the values placed on working outside current norms.

According to O'Brien, Millis and Cohen, problem based learning provides students with a stronger sense of motivation for 'sustained inquiry'. The difficulty with an investigation into 'messy' problems that become too big or too complex, or work across challenges that are far beyond the scope of realistic investigative procedures for students at university and that too can be de-motivating. What is important - and can on occasion be missed by lecturers who use problem based learning — is the provision of appropriate, cumulative activities in initial investigative framing (which is an in-depth, researched process itself). Re-framing and directed research informing design development has to continue throughout the investigation and then on throughout the course to provide method, structure and research tools for creative learning without undermining the student's role in driving the project. 'Successful courses balance the challenges to think critically with support tailored to students' developmental needs' (O'Brien, J., Millis, B., Cohen, M., 2008). The challenge is in developing learning opportunities that allow appropriate settings for the application of divergent / convergent thinking, within project work, based on the complexities of the different design ontology that have developed over the last decade. This requires stimulus, incremental learning activities, and assessment that reflect the ideals of the different ontology and do not restrict the students' creativity through pre-framing of the problem and conventional thinking.

\section{Creating a cognitive apprenticeship approach for authentic learning for new creative thinking.}

To re-imagine the possible futures of the world, and be able to think genuinely creatively about their world, students' thinking has to undergo a fundamental change. This can be very disorienting for students straight from the school system. Therefore, it is necessary to introduce concepts incrementally to support learning across the cohort. Attitudes may then be remodeled through learning practical creative methods, by applying those methods in authentic learning situations and thereby increasing self-confidence. This has been termed creative learning (Craft 2006) and implies a form of apprenticeship. The cognitive apprenticeship model strives to 'make thinking visible' by breaking down process into repeatable steps, emphasizing context, conceptual modeling, and transfer of skills - 
generalizability (Collins, Brown and Holim 1991). A cognitive apprenticeship method can contribute to a re-imagining of creative thinking practice and education, where students are equipped with the ability to respond to the world holistically. This is especially important when set against a backdrop of design futures thinking that require teachers and students to consciously discard preconceptions and conventions.

In addition to formative lecturer and peer feedback during the course, to become creatively successful the student will need to develop the ability to critically self-assess their progress (Jackson, Sinclair 2006). Lubert found students who self-assess early in the creative process, and frequently thereafter, show higher levels of creative output (Lubert 2001). While teacher expectations in student performance tend to rise progressively as the student gains confidence, it is essential that any gap between lecturer expectation and student capability can be identified and bridged during the course to maintain confidence in the new project settings where uncertainty could easily lead to insecurity.

\section{Practical assessment instrument}

In the same way that the quality of a design in an educational context is most effectively assessed in relation to the design intent, so assessment of creativity needs to be valued within a context, even where learning is cumulative and assessed formatively as well as summatively. Assessing incrementally, in tandem with introducing concepts incrementally, helps to manage this process. Attitudes may then be remodeled through learning practical creative methods, applying them and increasing self-confidence. From a practical, in-theclassroom perspective, a framework is needed that as well as being applicable to students' creative outcomes is also indicative of how far these outcomes may be evolved. The 'Propulsion' model, for example, does this by identifying eight types of creative contribution: (1) Replication, (2) Redefinition, (3) Forward incrementation, (4) Advanced forward incrementation, (5) Redirection, (6) Reconstruction/Redirection, (7) Reinitiation, and (8) Integration (Sternberg, Kaufman, and Pretz, 2001; 2002; 2004). This model recognizes different levels of creative output and provides a general assessment instrument. A design-orientated approach takes into account the designed outcome and provides appropriate criteria, and various attempts have been made to address this from within the fields of creative arts and design (Balchin, 2006; Cowdroy and de Graaf, 2005; Cowdroy and Williams, 2006; Ellmers, Foley and Bennett, 2008; Welch, 2008). 
One workable instrument created for use in an engineering design context, is the Cropley \& Cropley Solution Diagnosis Scale (Cropley and Cropley, 2009). This model incorporates a scale of creativity against indicators that identify stages in the process as well as final product. The scale begins by situating work against the known and progressively compares it with attributes of originality and likely effect upon the field. The key indicators, each of which have sub-qualities, are: (a) Relevance and Effectiveness, which considers the concept in terms of routine solution; (b) Novelty considers the outcome in terms of originality and whether it adds to existing knowledge or is developing new knowledge; (c) Elegance in terms of external and internal elegance of solution, and; (d) Generalizability in terms of ideas that go beyond the immediate problem. Set criteria allow students to understand explicitly how they are assessed and provide a 'reference framework'. They provide a framework that, at least initially, instrumentally supports students until they become sufficiently selfconfident and progressively self-regulatory. Set criteria, however, remain problematic and incur significant disadvantages compared with holistic assessment (Sadler 2009) and therefore should be used as the means to an end and not as an end in themselves. The goal is for students to formulate their own problems and set their own standards.

The aim of feedback is to facilitate learning by providing the best possible information to the student through identifying and explaining elements of creativity that apply to a particular process or product. There are other issues that need consideration, such as contrasting assessment with the quality assurance discourse (Harman and McDowell, 2011) and considering reliability and validity, with every measure of assessing creativity (Starko 2010). In broader terms, along with a bias towards psychometrics, assessment has been criticised for not being sufficiently interdisciplinary (Plucker, Makel 2010). Finally, the assessment of creative outcomes should relate to a clear meta framework that provides coherence and meaning to outcomes within social structures.

\section{Conclusion}

The impact of design decisions on economies, the environment and societies is being increasingly understood and the professional practice of design is facing challenges as a result. Design education has the opportunity to direct and support positive change in the discipline but predicting the agency of objects, mapping new business practices for new ways of working with value chains, rethinking the interaction of people and design requires new ways of working. Current theory in design education includes a myriad of approaches 
to practice that predominantly move design towards strategic thinking. Whether this is right or wrong, or whether it will be sustained in the face of economic pressures, is a separate discussion, but in addition to proposing the shift in education from situational design embedded in profession based thinking towards strategic thinking on complex, transdisciplinary problems, there needs to be an accompanying discourse on practical tools and approaches for supporting learning for these complex issues. This is not contradictory, but neither is it straight forward. Design academics need to re-think the conventional tools for creative thinking and consider how to provoke and support a holistic approach to creativity. In doing so, the fundamentals of learning and teaching still apply - students need to be provided with cumulative learning activities within an overall significant learning framework that allow them to become self reliant, confident learners even within projects outside the lecturers field of expertise that are increasingly 'messy'. For creative thinking a cognitive apprenticeship model, supported by incremental formative assessment, both external and self-reflective, as suggested in this article, could potentially provide students with the tools to tackle the increasing complexities and uncertainties of the new design curriculum models. Creativity is at the heart of any new thinking approach within design. A considered approach to applying creative thinking in ways that support the development of students' abilities to re-imagine the future will help make the idea a reality.

The teaching of creative thinking has often be trivialized by faculty, industry and even students themselves because of the fundamental necessity of accessing the right hemisphere of the brain in addition to the dominant, logical left in order to develop creative thinking skills. Thinking creatively often requires kinesthetic and mental activities that conflict with habitual ideas of 'real', 'serious' or 'important' work. Yet design is fundamentally creative thinking based on directed research. The content of the design curriculum in higher education is becoming increasingly abstract and based on concepts that have not evolved from past knowledge and understanding of the discipline. While this encompasses thinking from other disciplines and requires alternative approaches to framing investigation, creative thinking is still the primary skill needed to operate effectively in the new learning environment. Understanding where creative thinking in recent education came from and what it consists of, and then considering it in relation to the change in design education and also in terms of the growth of understanding of learning and teaching, provides the basis for an appropriate approach to supporting students in re-imagining a designed future. 
The challenge is to assert, or in some cases reassert, the fundamental significance of creative thinking in the design curriculum. It is important that the role and value of creative thinking in meeting new meta design objectives is clarified in order that students and faculty are more prepared to invest time and effort into developing authentic approaches to it. Only through this understanding and visible mapping will the incremental practical activities that develop the skills needed for new ways of creative thinking, and of learning creative thinking, be embraced by the stakeholders and achieve their appropriate place in the curriculum.

\section{References}

Asimov, Isaac (1987), Nine Tomorrows, New York: Del Ray.

Balchin, Tom (2006), Evaluating creativity through consensual assessment, in Developing Creativity in Higher Education N. Jackson, M. Oliver, M. Shaw, J. Wisdom eds. London: Routledge.

Biggs, J. Tang, C (2011) Teaching for Quality Learning at University, Maidenhead: OUP Calwelti, S. Rappaport, A. and Wood, B. (1992), Modeling artistic creativity: An empirical study. Journal of Creative Behavior, 26 (2), pp.83-94.

Clegg. B. Birch, P. (2002), Crash Course in Creativity. London: Kogan Page.

Collins, A. Brown, J.S. Holim, A. (1991), Cognitive apprenticeship: Making thinking visible. American Educator. Winter Issue, Washington DC: American Federation of Teachers, pp.118.

Cowdroy, R. and de Graaf, E. (2005), Assessing highly-creative ability. Assessment \& Evaluation in Higher Education, 30 (5), Taylor Francis Online. Accessed 10 May 2008. Cowdroy, R. Williams, A. (2006), Assessing creativity in the creative arts. Art, Design \& Communication in Higher Education, 5 (2), Art Full Text (H.W.Wilson). Accessed 10 May 2008.

Craft, A. (2006), Creativity in schools, N. Jackson, M. Oliver, M. Shaw, \& J. Wisdom, eds. Developing Creativity in Higher Education: An imaginative curriculum. Oxford: Routledge.

Craft, A. (2008), Trusteeship, wisdom and the creative future of education, The UNESCO Observatory E-Journal, 1 (3) http://www.education.unimelb.edu.au/eldi/elc/unesco/ejournal/index.html. Accessed 23 
April 2012.

Cropley, A. Cropley, D. (2009), Fostering Creativity: A diagnostic approach for Higher Education and Organizations. Cresskill, NJ: Hampton Press.

De Bono, E. (1990), Lateral Thinking: Creativity Step By Step. New York: Harper \& Row de Vere, I. (2011), An ethical stance: Engineering curricula designed for social responsibility, International Conference on Engineering Design ICED11, 15-18 Aug. Copenhagen: Technical University of Denmark.

Ellmers, G. Foley, M. Bennett, S. (2008), Graphic design education: A revised assessment approach to encourage deep learning. Journal of University Teaching and Learning Practice. 5 (1), http://ro.uow.edu.au/jutlp/. Accessed 11 November 2011.

Fry, T. (2011), Design as Politics New York: Berg

Fuad Luke, A. (2009), Design Activism: Beautiful strangeness in a sustainable world, New York: Routledge.

Gabora, L. (2010), Revenge of the "Neurds": Characterizing creative thought in terms of the structure and dynamics of memory. Creativity Research Journal, 22 (1), Taylor and Francis Social Science and Humanities Library. Accessed 20 June 2010.

Guilford, J.P. (1950), Creativity. American Psychologist, 5, Washington, D.C.: American Psychologist Association. pp.444-454.

Harman, K. McDowell, L. (2011), Assessment talk in Design: the multiple purposes of assessment in HE. Teaching in Higher Education, 16 (1), Taylor and Francis Social Science and Humanities Library. Accessed 13 February 2011.

Hawken, P. Lovins, A. Lovins, L. Hunter, (2008), Natural Capitalism, Creating the Next Industrial Revolution, London: Back Bay Books.

Jackson, N. Sinclair, C. (2006), Developing student's creativity: searching for an appropriate pedagogy in: Jackson, N., Oliver, M., Shaw, M., \& Wisdom, J. [eds] Developing Creativity in Higher Education: An imaginative Curriculum. Oxford: Routledge.

Loy, J. (2012), Creating confidence in an alienating educational environment, Design Education for Future Wellbeing, $14^{\text {th }}$ International Conference on Engineering and Product design Education, A Kovacevic, W Ion, C McMahon, L Buck, P Hogarth, eds. Wilts: Institute of Engineering Designers. 
Lubert, T.I. (2001), Models of the Creative Process: past present and future. Creativity Research Journal, 13, (3-4), Informa Ltd. Accessed 31 March 2012.

McGilchrist, I. (2010), The Master and His Emissary: The divided brain and the making of the western world. New Haven: Yale University Press.

Michalko, M. (2006), Thinkertoys: A handbook of business creativity. Berkeley, CA: Ten Speed Press.

O’Brien, J. Millis, B. Cohen, M. (2008), The Course Syllabus San Francisco: Wiley and Sons.

Osborn, A.F. (1963), Applied Imagination: Principles and Procedures of Creative Problem Solving. $3^{\text {rd }}$ ed. New York: Charles Scribner's Sons.

Plucker, J.A. Makel, M.C. (2010), Assessment of creativity, Kaufman, J.C. and Sternberg, R.J. [eds] 2010. The Cambridge Handbook of Creativity. New York: Cambridge University Press, Ch.3.

Pricken, M. (2002), Creative Advertising: Ideas \& techniques from the world's best campaigns. London: Thames \& Hudson.

Ramsden, P. (2003) Learning to Teach in Higher Education $2^{\text {nd }}$ Ed. New York: Routledge. Sadler, D.R. (1989), Formative assessment and the design of instructional systems. Instructional Science, 18, SpringerLINK Archive. Accessed 31 March 2012.

Sadler, D.R. (1998), Formative assessment: revisiting the territory. Assessment in Education: 5, (1), ProQuest Central. Accessed 31 March 2012.

Sadler, D.R. (2009), Transforming holistic assessment and grading into a vehicle for complex learning, G. Joughin [ed.], Assessment, Learning and Judgement in Higher Education. Ebrary Inc. Ch.4. Accessed 27 February 2009.

Starko, A.J. (2010), Creativity in the Classroom: Schools of curious delight [4th ed]. New York: Routledge.

Sternberg, R.J. Lubart, T.I. (1995), Defying the crowd: Cultivating creativity in a culture of conformity. New York: Free Press.

Sternberg, R.J. Kaufman, J.C. Pretz, J.E. (2001), The propulsion model of creative contributions applied to the arts and letters. Journal of Creative Behavior, [e-journal] 35, Wiley-Blackwell Journals. Accessed 9 March 2012. 
Sternberg, R. J. Kaufman, J. C. Pretz, J. E. (2002), The Creativity Conundrum: A propulsion model of kinds of creative contributions. New York: Psychology Press,

Sternberg, R.J. Kaufman, J.C. Pretz, J.E. (2004), A propulsion model of creative leadership. Creativity \& Innovation Management, 13, (3), Wiley-Blackwell Journals. Accessed 9 March 2012.

Stevens, D. Levi, A. (2005), Introduction to Rubrics Virginia: Stylus Publishing.

Tatum, J. (2004), The challenge of responsible design Design Issues Summer 2004, Vol. 20, No. 3, Pages 66-80. Massachusetts: Massachusetts Institute of Technology.

Treffinger, D.J. Isaksen, S.C. Stead-Dorval, K.B. (2006), Creative Problem Solving: An introduction. $4^{\text {th }}$ ed. Wacol: Prufrock Press,

Walker, S. (2002), A journey in design: an exploration of perspectives for sustainability. The Journal of Sustainable Product Design, 2. Online: SpringerLink.

Weimer, M. (2002), Learner-Centered Teaching: Five Key Changes to Practice San Francisco: Jossey Bass.

Welch, D.J.A. (2008), Edging closer to the creative core, Australian Council of University Art and Design Schools Conference, Sites of Activity/On the Edge, Adelaide 1-3 October 2008, http://www.acuads.com.au/. Accessed 25 June 2012.

Wood, J. (2007), Design for Micro-Utopias: Making the unthinkable possible. Aldershot: Gower. 